\title{
Nickel-on-Charcoal-Catalyzed Reductions of Aryl Chlorides
}

\author{
Bruce H. Lipshutz, * Takashi Tomioka, Kimihiko Sato \\ Department of Chemistry \& Biochemistry University of California, Santa Barbara, CA 93106, USA \\ Fax +1 805 8938265; E-mail: lipshutz@chem.ucsb.edu \\ Received 26 January 2001 \\ Warmly dedicated to Professor Ryoji Noyori in recognition of his outstanding contributions to synthetic organic chemistry
}

\begin{abstract}
Exposure of (functionalized) aryl chlorides to catalytic quantities of nickel-on-charcoal in the presence of stoichiometric amounts of $\mathrm{Me}_{2} \mathrm{NH} \cdot \mathrm{BH}_{3} / \mathrm{K}_{2} \mathrm{CO}_{3}$ in refluxing acetonitrile leads to high yields of reduced arenes. PCBs are also reduced under these conditions. The method is highly tolerant of moisture.
\end{abstract}

Key words: aryl chlorides, dechlorination, heterogeneous catalysis, nickel-on-charcoal

Reduction of an aryl chloride to the corresponding arene is usually accomplished via a process involving palladium catalyzed transfer hydrogenation using formic acid or its salts as the source of hydrogen. ${ }^{1}$ While several other methods have appeared over the years which, likewise, effect a net aryl C-Cl to C-H conversion $\left\{\right.$ e.g., Raney $\mathrm{Ni}^{2}{ }^{2}$ " $\mathrm{KCuH}_{2},{ }^{3}$ cat $\mathrm{Ni}(\mathrm{II}) / \mathrm{Zn}(0) / \mathrm{EtOH},{ }^{4}$ cat $\mathrm{Pd}(0) / \mathrm{NaOCH}_{3},{ }^{5}$ cat $\mathrm{NiCl}_{2} / \mathrm{MgH}_{2},{ }^{6}$ cat $[\mathrm{Ru}] / s-\mathrm{BuOH},{ }^{7}$ cat $[\mathrm{Rh}] / \mathrm{HSiEt}_{3},{ }^{8}$ cat $\mathrm{Cp}_{3} \mathrm{La} / \mathrm{NaH},{ }^{9}$ and cat $\left.\mathrm{Cp}_{2} \mathrm{TiCl}_{2} / \mathrm{RMgBr}\right\},{ }^{10}$ functional group compatibility is rarely addressed. Many reflect development driven by environmental issues, specifically the goals of modifying dioxins and PCBs, ${ }^{11}$ where only reduction of the carbon-chlorine bond(s) is of paramount concern. In fine chemicals synthesis, however, clean and chemoselective reductive methods which involve neutral conditions and thus tolerate a variety of functionality, especially electrophilic centers, could prove to be quite valuable. For example, nature provides a plethora of chlorinated, physiologically active compounds, ${ }^{12}$ including such topical examples as the antitumor agent cryptophycin $1^{13}$ and the clinically critical antibiotic vancomycin ( $c f$. aglycon below), ${ }^{14}$ the des-chloro derivatives of which might be of interest from the perspective of structure-activity relationships.

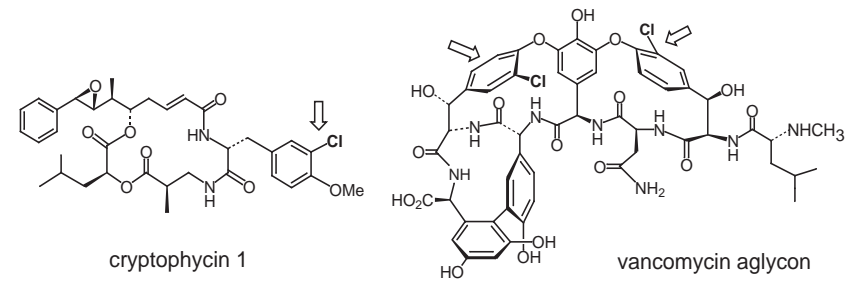

Figure 1

Moreover, a relatively strong $\mathrm{C}-\mathrm{Cl}$ bond could be viewed as a blocking group for an aryl site, and/or it might also function stereoelectronically to direct electrophilic attack onto an aryl ring. We now describe an operationally simple, environmentally friendly, and inexpensive method for reducing aryl chlorides using nickel on charcoal as catalyst (Scheme 1).

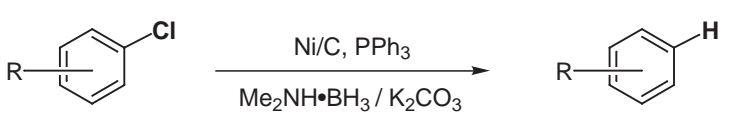

Scheme 1

Previously, we have demonstrated that readily prepared $\mathrm{Ni} / \mathrm{C}$ is highly effective at catalyzing $\mathrm{C}-\mathrm{C}$ bond constructions of the Negishi, ${ }^{15 a}$ Kumada, ${ }^{15 b}$ and Suzuki ${ }^{15 c}$ types. More recently, $\mathrm{Ni} / \mathrm{C}$ has been shown to catalyze aminations of aryl chlorides. ${ }^{16}$ In turning our attention to a reductive process which could take advantage of the ability of $\mathrm{Ni}(0)$ to oxidatively insert into an aryl-chlorine bond, it seemed reasonable that a suitable source of hydride could be found which would participate in the catalytic cycle. Our initial attempts utilizing $\mathrm{H}_{2}$ at atmospheric pressure or above (up to 27 psi in a Parr hydrogenator) ${ }^{17}$ were fruitless (i.e., no reaction occurred), as were reactions employing either $\mathrm{HCO}_{2} \mathrm{H}$ or $\mathrm{HCO}_{2} \mathrm{NH}_{4} \cdot{ }^{1}$ Products of reduction could be obtained in simple systems using Red-Al, although functional group compatibility is likely to be compromised with this potent hydride source on more highly derivatized cases. Excellent results were eventually noted using a commercially available, inexpensive amineborane ${ }^{18}$ in the presence of $\mathrm{K}_{2} \mathrm{CO}_{3}$. Thus, treatment of an aryl chloride with 1.1 equivalents of both $\mathrm{Me}_{2} \mathrm{NH} \cdot \mathrm{BH}_{3}$ and $\mathrm{K}_{2} \mathrm{CO}_{3}$ under the influence of $5 \% \mathrm{Ni} / \mathrm{C}$ and $20 \%$ triphenylphosphine in refluxing acetonitrile required only 510 hours to effect complete reduction. Further streamlining this methodology is the fact that prior reduction of the $\mathrm{Ni}(\mathrm{II}) / \mathrm{C}$ to $\mathrm{Ni}(0) / \mathrm{C}$ with two equivalents (i.e., $10 \mathrm{~mol} \%$ ) of $n$-BuLi in an inert solvent (e.g., THF) ${ }^{15}$ is not necessary. Thus, the slight excess of $\mathrm{Me}_{2} \mathrm{NH} \cdot \mathrm{BH}_{3} / \mathrm{K}_{2} \mathrm{CO}_{3}$ (i.e., $10 \mathrm{~mol} \%$ ) being used is presumably responsible for in situ generation of the catalyst in active zero valent form.

Table 1 illustrates several representative aryl chlorides examined, including those bearing electrophilic centers (entries 7, 8 and 10). Considering that a nitrile is used as solvent, clearly this residue is inert as well (entries 1 and 2). Based on the observation that relatively acidic protons on nitrogen in amide $\mathbf{2}$ and indole $\mathbf{3}$ did not interfere, an experiment was conducted using moist acetonitrile as the 
Table 1 Representative Reductions of Aryl Chlorides Using 5\% $\mathrm{Ni} / \mathrm{C}+20 \% \mathrm{PPh}_{3}$ as Catalyst

Entry

${ }^{a}$ By quantitative GC. 'Isolated yield.

reaction medium. Treatment of 1 in $2 \%$ aqueous $\mathrm{CH}_{3} \mathrm{CN}$ under otherwise identical conditions ( $c f$. Table 1, entry 1), afforded the desired reduced arene quantitatively (Scheme 2).
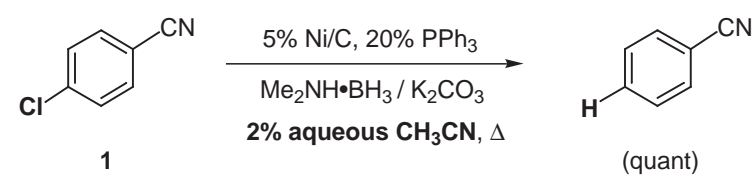

Scheme 2

Substrates bearing ortho-substituents were smoothly reduced (entries 2, 6, and 10), while both electron-rich and electron-poor cases (entries 4 and 7, respectively) afforded similar results at surprisingly similar rates. Several of the above observations are embodied in the efficient conversion of a chlorinated racemic biaryl ether to its dechlorinated derivative 4 (entry 10). Phenylalanine methyl ester $5\left\{[\alpha]_{\mathrm{D}}^{25}=-63.7^{\circ}\left(\mathrm{c}=1.1,95 \% \text { EtOH; lit }-64^{\circ}\right\}^{19}\right.$ could be smoothly reduced to 6 in high isolated yield essentially without loss of optical purity $\left\{[\alpha]_{D}{ }^{25}=-44.4^{\circ}(\mathrm{c}=1.0\right.$, 95\% EtOH; lit. $-45.3^{\circ} ;{ }^{19} 98 \%$ ee; Scheme 3$\}$. This method is limited, however, to non-aldehyde- and -ketone-containing educts, as $p$-chlorobenzophenone led mainly to diphenylcarbinol.
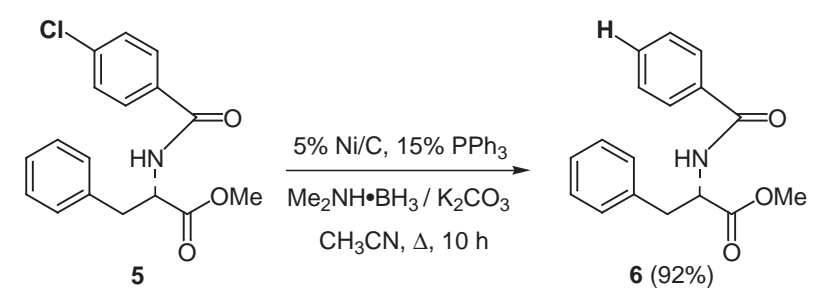

Scheme 3

Application of this Ni/C-amine-borane combination to reductions of (poly)chlorinated biphenyls (PCBs) ${ }^{11}$ was also possible. Mono-, di-, and trichlorobiphenyls, (7-9, respectively) were all successfully converted to biphenyl (Figure 2). ${ }^{20}$ In the case of $\mathbf{9}$, however, incomplete reduction was observed even after 36 hours, the remaining material consisting of ortho-chlorobiphenyl.

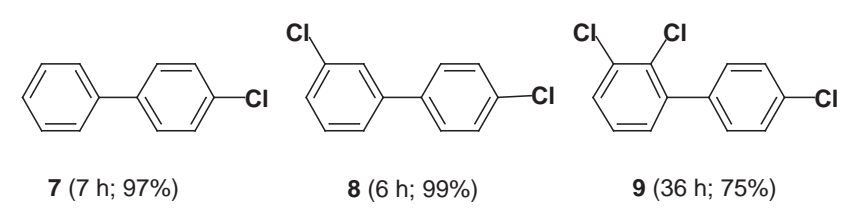

Figure 2

Prior experience with $\mathrm{Ni}(0) / \mathrm{C}$ suggests that a phosphine ligand (usually $\mathrm{PPh}_{3}$ ) is required for a synthetically useful level of conversion, and ultimately, isolated yield. ${ }^{15}$ Typically, 3-4 equivalents are needed relative to the percentage of nickel loaded onto the solid support, an assumption used in carrying out the examples illustrated in Table 1. Although seemingly the norm for $\mathrm{Ni}(0) / \mathrm{C}$-mediated C-C bond constructions, it is not obvious that a reductive process will have identical requirements. ${ }^{16}$ Indeed, in the test case of $p$-chlorobenzonitrile (1, Table 2$)$, only two equivalents of $\mathrm{PPh}_{3}$ relative to nickel were needed to obtain the desired product quantitatively. Moreover, the rate of this reduction was actually somewhat faster than that noted under conditions where twice the amount of phosphine (i.e., 4 equivalents) was present ( $c f$. Table 1 , entry 1 ). In the complete absence of phosphine, the level of conversion was dramatically reduced. 
Table 2

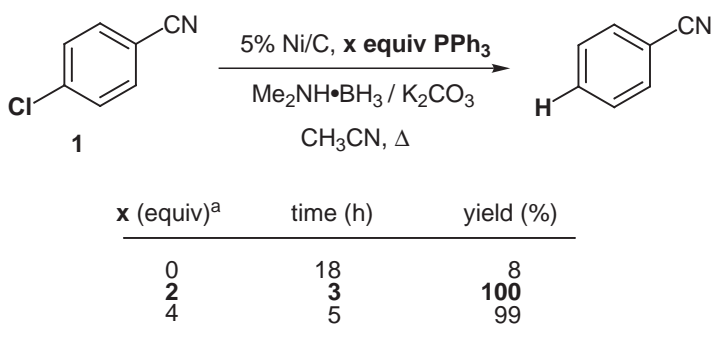

${ }^{a}$ relative to nickel

In an attempt to broaden the scope of this process, a silane was envisioned as a particularly mild donor of hydride. Tetramethyldisiloxane (TMDS) ${ }^{21}$ was therefore selected to serve in this capacity. Although reduction of chloroketone $\mathbf{1 0}$ to benzophenone required higher temperatures (i.e., refluxing dioxane), it took place very efficiently and without competitive 1,2-carbonyl addition (Scheme 4). Unfortunately, it was found that a considerable amount of nickel had bled off the solid support. Thus, whereas analyses via inductively coupled plasma (ICP) ${ }^{22}$ indicated that reductions involving an amine-borane led to at most a $3 \%$ loss of nickel from the $5 \% \mathrm{Ni} / \mathrm{C}$ being used, $80 \%$ of the $\mathrm{Ni}$ (II) which had been mounted on charcoal and used as catalyst in the reaction of $\mathbf{1 0}$ could be detected in the aqueous sample prepared from the filtrate of the crude reaction mixture involving TMDS.<smiles>O=C(c1ccccc1)c1ccc(Cl)cc1</smiles>

10
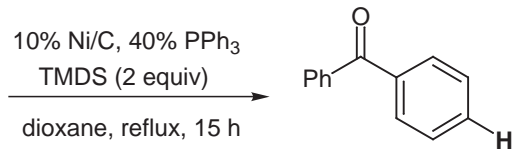

$(96 \%)$
Scheme 4

This catalyst bleeding appears to be an unusual and unexpected phenomenon characteristic (thus far) exclusively of silanes, as similar observations were made when TMDS was replaced by polymethylhydrosiloxane (PM$\mathrm{HS})^{23}$ or $\mathrm{Et}_{3} \mathrm{SiH}$.

Finally, the question of catalyst-recycling has been addressed using this procedure for aryl chloride reductions. Thus, upon completion of the reduction of $\mathbf{1}$, filtration of the reaction mixture through a sintered glass frit allowed for recovery of the spent $\mathrm{Ni} / \mathrm{C}$. This marterial was subjected to two additional reaction cycles using fresh substrate and amine-borane to afford essentially identical results (Scheme 5).

In summary, a new method has been developed which allows for high yield reductions of aryl chlorides to the corresponding arenes mediated by the heterogeneous catalyst $\mathrm{Ni} / \mathrm{C} .^{24}$ The procedure involved is straightforward and especially forgiving with respect to levels of moisture present in the medium. Reaction work-up is particularly

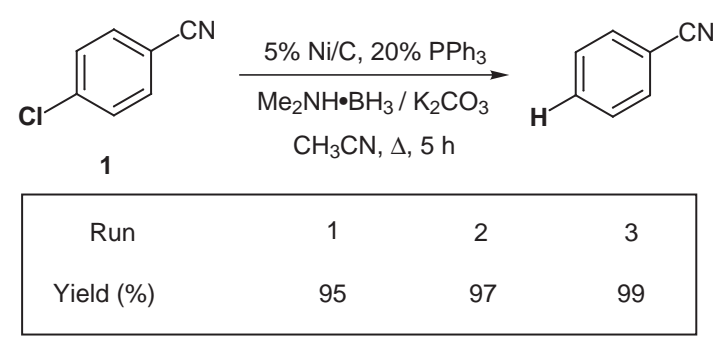

Scheme 5

simple (i.e., filtration and solvent evaporation), as is characteristic of this type of catalysis. Several of the more common electrophilic functional groups of interest are tolerated, ${ }^{25}$ only stoichiometric amounts of hydride are needed (1.0 equivalent relative to substrate), and given the likely in situ generation of the kaliated form of $\mathrm{Me}_{2} \mathrm{NH} \cdot \mathrm{BH}_{3}$, the reaction conditions are essentially neutral.

\section{Acknowledgement}

We warmly thank the NSF (97-34813) for support of our programs.

\section{References and Notes}

(1) (a) Pandey, P. N.; Purkayastha, M. L. Synthesis 1982, 876. (b) Cortese, N. A.; Heck, R. F. J. Org. Chem. 1977, 42, 3491. (c) Wiener, H.; Blum, J.; Sasson, Y. ibid. 1991, 56, 6145. (d) Rajagopal, S.; Spatola, A. F. ibid. 1995, 60, 1347.

(2) (a) Tashiro, M.; Fukata, G.; Oe, K. Org. Prep. Proceed. Int. 1975, 7, 183. (b) Liu, G-B.; Tsukinoki, T.; Kanda, T.; Mitoma, Y.; Tasiro, M. Tetrahedron Lett. 1998, 39, 5991.

(3) Yoshida, T.; Negishi, E. J. Chem. Soc., Chem. Comm. 1974, 762.

(4) (a) Colon, I. J. Org. Chem. 1982, 47, 2622. (b) Sakai, M.; Lee, M-S.; Yamaguchi, K.; Kawai, Y.; Sasaki, K.; Sakakibara, Y. Bull. Chem. Soc. Jpn. 1992, 65, 1739.

(5) (a) Zask, A.; Helquist, P. J. Org. Chem. 1978, 43, 1619. (b) Zoran, A.; Sasson, Y.; Blum, J. J. Mol. Catal. 1984, 27, 349.

(6) (a) Carfagna, C.; Musco, A.; Pontellini, R. J. Mol. Catal. 1989, 57, 23. (b) Carfagna, C.; Musco, A.; Pontellini, R. ibid. 1990, 63, L1.

(7) Cucullu, M. E.; Nolan, S. P.; Belderrain, T. R.; Grubbs, R. H. Organometallics 1999, 18, 1299.

(8) Esteruelas, M. A.; Herrero, J.; Lopez, F. M.; Martin, M.; Oro, L. A. Organometallics 1999, 18, 1110.

(9) Qian, C.; Zhu, D.; Gu, Y. J. Mol. Catal. 1989, 54, L23.

(10) Hara, R.; Sato, K.; Sum, W.-H.; Takahashi, T. Chem. Commum. 1999, 845.

(11) (a) Yale, M.; Keen, C.; Bell, N. A.; Drew, P. K. P.; Cooke, M. Appl. Organomet. Chem. 1995, 9, 297. (b) Tabaei, S.-H. H.; Pittmann, C. U.; Mead, K. T. J. Org. Chem. 1992, 57, 6669. (c) Lassova, L.; Lee, H. K.; Hor, T. S. A. ibid. 1998, 63, 3538. (d) Liu, Y.; Schwartz, J. Tetrahedron 1995, 51, 4471.

(12) Gribble, G. W. Acc. Chem. Res. 1998, 31, 141.

(13) Liang, J.; Moher, E. D.; Moore, R. E.; Hoard, D. W. J. Org. Chem. 2000, 65, 3143.

(14) (a) Evans, D. A.; Wood, M. R.; Trotter, W.; Richardson, T. I.; Barrow, J. C.; Katz, J. L. Angew. Chem. Int. Ed. 1998, 37, 2700. (b) Nicolaou, K. C.; Natarajan, S.; Li, H.; Jain, N. F.; 
Hughes, R.; Solomon, M. E.; Ramanjulu, J. M.; Boddy, C. N. C.; Takayanagi, M. ibid. 1998, 37, 2708. (c) Boger, D. L.; Miyazaki, S.; Kim, S. H.; Wu, J. H.; Loiseleur, O.; Castle, S. L. J. Am. Chem. Soc. 1999, 121, 3226.

(15) (a) Lipshutz, B. H.; Blomgren, P. A. J. Am. Chem. Soc. 1999, 121, 5819. (b) Lipshutz, B. H.; Tomioka, T.; Blomgren, P. A.; Sclafani, J. A. Inorg. Chim. Acta 1999, 296, 164. (c) Lipshutz, B. H.; Sclafani, J. A.; Blomgren, P. A. Tetrahedron 2000, 56, 2139.

(16) Lipshutz, B. H.; Ueda, H. Angew. Chem. Int. Ed. 2000, 39, 4492.

(17) Yakovlev, V. A.; Terskikh, V. V.; Simagina, V. I.; Likholobov, V. A. J. Mol. Catal. A; Chem. 2000, 153, 231.

(18) (a) Lipshutz, B. H.; Buzard, D. J.; Vivian, R. W. Tetrahedron Lett. 1999, 40, 6871. (b) Carboni, B.; Monnier, L. Tetrahedron 1999, 55, 1197.

(19) Gelbard, G.; Kagan, H. B.; Stern, R. Tetrahedron 1976, 32 , 236.

(20) For both $\mathbf{7}$ and $\mathbf{8}, 5 \% \mathrm{Ni} / \mathrm{C}$ was used, while for $\mathbf{9}$, a higher loading of $\mathrm{Ni} / \mathrm{C}(7.5 \%)$ was employed in hopes of driving this reaction to completion.

(21) Trost, B. M.; Braslau, R. Tetrahedron Lett. 1989, 30, 4657.
(22) Inductively Coupled Plasma Mass Spectrometry, (Ed. Montaser, A.), Wiley-VCH, New York, 1998.

(23) Lawrence, N. J.; Drew, M. D.; Bushnell, S. M. J. Chem. Soc., Perkin Trans. 1 1999, 3381.

(24) General procedure for reduction of aryl chlorides: To a flamedried $10 \mathrm{~mL}$ round-bottomed flask under a blanket of argon at room temperature were added $\mathrm{Ni}(\mathrm{II}) / \mathrm{C}$ ( $69 \mathrm{mg}, 0.05 \mathrm{mmol}$, $0.73 \mathrm{mmol} / \mathrm{g}$ ), triphenylphosphine $(52 \mathrm{mg}, 0.20 \mathrm{mmol}), 98 \%$ borane-dimethylamine complex (66 $\mathrm{mg}, 1.1 \mathrm{mmol})$, and potassium carbonate $(152 \mathrm{mg}, 1.1 \mathrm{mmol})$. Dry, deoxygenated acetonitrile $(2 \mathrm{~mL})$ was added via syringe and the slurry allowed to stir for $2.5 \mathrm{~h}$. Aryl chloride $(1.0 \mathrm{mmol})$ and an internal standard $(1.0 \mathrm{mmol})$ were added with swirling, and the mixture was then heated to reflux in a $100{ }^{\circ} \mathrm{C}$ sand bath. Upon completion, the mixture was filtered through a silica gel-glass wool plug loaded into a disposable pipet, and the filtrate was analyzed by GC.

(25) We have recently observed that isolated olefins, unfortunately, are reduced under these conditions.

Article Identifier:

1437-2096,E;2001,0,SI,0970,0973,ftx,en;Y02901ST.pdf 